\title{
Historical notes on anisotropy
}

\author{
Giovanni Ferraris ${ }^{1,2}$
}

Published online: 16 January 2020

(c) Accademia Nazionale dei Lincei 2020

Rendiconti Lincei. Scienze Fisiche e Naturali has recently started publishing papers assembled as Topical Collections (Aquilanti and Mottana 2019). In particular, under the heading "Physicochemical properties of matter" it is intended to group together those contributions that are dedicated to the study of physical and chemical aspects of matter as it manifests in its various states.

The occasion to propose the new Topical Collection, of which I have been asked to act as Editor, was the conference "Anisotropic properties of matter" held in Rome at Accademia Nazionale dei Lincei on October 16-17 2019 with the participation of speakers from several main areas of science, as clearly shown by the following list of communications: Mottana, How single-crystal properties discovered by Danes changed the outlook of mineralogy and solid state physics; Compagnoni, Topical interest of crystallographic optics in the study of minerals and transparent synthetic phases; Nestola, The importance of anisotropy in determining the depth of formation of the diamond-inclusion natural system; Bindi, Natural versus synthetic quasicrystals: Analogies and differences in the optical behaviour of icosahedral and decagonal quasicrystals; Margheriti, Seismic anisotropy of the Earth's mantle and crust; Fallani, Anisotropy in the quantum world: from quantum optics to new ultracold "anisotropic" matter; Marcellini, Anisotropic and p, q-nonlinear partial differential equations; Zecchina, Potential role of asymmetric catalysis by quartz and calcite chiral surfaces in the origin of homochirality; Geppi, Anisotropy and NMR spectroscopy; Aquilanti, Stereodirected beams of molecules: anisotropies, chirality; Bolognesi, (A)symmetry and (pseudo)crystalline

This paper is based on the introductory speech given by the author at the Conference "Anisotropic properties of matter" held at Accademia Nazionale dei Lincei, Rome, October 16-17, 2019.

Giovanni Ferraris

giovanni.ferraris@unito.it

1 Dipartimento di Scienze della Terra, Università di Torino, Turin, Italy

2 Accademia Nazionale dei Lincei, Rome, Italy state in macromolecular biological systems; Rerat, Non linear optical properties of crystalline compounds. First and second hyperpolarizability and the many related properties. Basic equations; Dovesi, Quantum mechanical simulation of the linear and non-linear properties of crystalline compounds. Tensors, symmetry, invariants; D'Arco, Dielectric tensor, refractive index, anisotropies and birefringence. And other third and fourth order tensors. Simulation vs experiment.

The conference, suggested by the occurrence of the 350th anniversary of the discovery of birefringence in a crystalline material (Bartholin 1669), showed that anisotropy continues to be a lively topic of both theoretical and applicative research. In this editorial, I briefly review the early investigations on anisotropy, a phenomenon that, like others, has its roots in the centuries-old interest for natural crystals (minerals) and, in particular, in attempts to link the morphology of crystals to their physicochemical behaviour (Burke 1966; Lima-de-Faria 1990; Mauskopf 1976).

Direction dependence of a physical property (anisotropy) is an intrinsic property of a non-random spatial distribution of matter, such as the atomic-scale order of the crystalline state, although, in certain cases, conditions of symmetry may impose isotropy: for example, the crystals belonging to the cubic system, although being anisotropic for most of the physical properties, are optically isotropic. Anisotropy can also appear in an amorphous solid to which an applied strain locally induces ordering of the atoms.

Actually, observation of properties that we now know to be anisotropic-such as cleavage (fracture according to preferential planes), hardness and morphology of crystals - had been reported since ancient times, e.g. by Plinius (23-79). It does not result, however, that valid hypotheses were formulated at that time to explain the behaviour of these properties, except perhaps some hints on the ordering of the atoms made in the fifth century BC by Leucippus and his pupil Democritus (Baur 2014). We need to get to the seventeenth century so that the atomic order is related to the directionality of physical properties. Even at the beginning of that century Kepler (1561-1630), 
fascinated by the hexagonal dendritic shape of snow crystals, wrote about it in a famous letter (Kepler 1611; Bartholin 1661), but, after having formulated some fanciful hypotheses, he gave up finding an explanation that satisfied him; yet, based on his pioneering theory of compact packing of spheres reported in the same letter, he would have had the means to propose sound hypotheses. It will be necessary to wait another half century before Hooke (1635-1703) clearly stated that regular morphology of the crystals must be connected with packaging of "globular particles" (Hooke 1665).

However, it will only be at the end of the eighteenth century that Haüy (1743-1822) will propose a systematic solution to the problem of the relationship between morphology and internal structure of crystals by hypotizing a structural model based on the triperiodic repetition of an indivisible and submicroscopic basic polyhedron that has the same composition as the crystal (Haüy 1784). In this pioneering work, Haüy called integrant molecule the basic module (responsible for the morphology of the crystal) and simple molecules its internal polyhedral components (responsible for the chemical composition).

To Galilei (1564-1642) it is unanimously attributed the merit of having opened the way to modern experimental science also thanks to the observation that, through his telescope, he made of the light coming from the stars. He was an early member of the Lincei Accademia and in 1614 he presented as a gift to the founder Cesi (1585-1630) a prototypical microscope to see details, e.g. of insects, but also of the shape of grains of sand. Soon, the investigation of luminous phenomena made scientific research take a decisive leap towards what is now known as the science of materials. I refer to the discovery of the birefringence of light—observed for the first time in Iceland spar (transparent calcite crystals) in 1669 by Bartholin (1625-1698) (Bartholin 1669) and subsequently explained in 1690 by Huygens (1629-1695) (Huygens 1690)—a phenomenon that showed how, in a crystalline material, the value of a physical quantity can be a function of direction.

Huygens explained the phenomenon of birefringence by means of a double hypothesis: the propagation of light by wave fronts and the triperiodic structure of calcite based on a compact packaging of iso-oriented ellipsoidal "atoms". Due to the anisotropy of the packaging, the speed of propagation of the wave front inside the crystal depends on the direction and, according to the proposed model, still substantially valid, the incident front splits into two fronts that propagate separately. The light rays associated with the two wave fronts are polarized and emerge from the crystal in two different directions. With the proposed structural model of calcite, it was explained the anisotropic behaviour of the four physical properties of the mineral then known: birefringence, hardness, cleavage and morphology.
Huygens had suspected that light refracted by calcite crystals had a further property, now known as polarization, which depends on the transverse direction to that of propagation. Of the same opinion were other scientists, but only in 1824 Fresnel (1788-1827) set the explanation of the phenomenon on a solid mathematical basis (Fresnel 1827).

The absence of a sound explanation of polarization did not prevent various scientists from observing its effects by analyzing the variation in intensity of reflected light transmitted by an oriented birefringent crystal (analyzer crystal). In this case, in fact, the light, being partially polarized, undergoes an absorption which is a function of the angle formed between its polarization direction and the transmission direction allowed by the analyzer. We can recall here Malus (1785-1812) who analyzed light reflected from glass windows of the Luxembourg Palace and introduced the term polarization (Malus 1809); Arago (1786-1853) who studied light coming from an intensely blue sky and from comets (Arago 1811); Biot (1774-1862) who examined the light of the rainbow and discovered anisotropic absorption of light and its dependence on wavelength (pleochroism) (Biot 1812,1817,1818).

Using polarized light, Arago and Biot discovered circular polarization (optical activity) in quartz and in certain liquids, respectively; however, the connection between circular polarization and crystal structure had to await the studies of Pasteur (1822-1895) on enantiomorphic tartrate crystals (Pasteur 1848). His explanation at atomic scale was that, as Fresnel had supposed in 1824 (Fresnel 1824), optical activity of a crystalline compound is determined by helical arrangement of groups of atoms / molecules in the structure. Based on Biot's observations on the absence of circular polarization in fused quartz and opal (i.e., in amorphous silica) (Biot 1839), Pasteur concluded that an optically active crystalline compound preserves this property in solution only if that is due to the spatial arrangement of its atoms (stereoisomerism, chirality) in a group (molecule) which survives the structure collapsing.

The observation of the anisotropic behaviour of crystals in light transmission opened the way to investigation on anisotropy regarding other physical properties. For example, Mitscherlich (1794-1863) described the anisotropic dilation of calcite (Mitscherlich 1824). It was, however, Cauchy (1789-1857) who profitably followed the mathematical method employed by Fresnel for the study of crystallographic optics and to describe elasticity in crystals using a three-by-three matrix now known as Cauchy stress tensor (Cauchy 1827). It took to wait for several years when Voigt (1850-1919), with the introduction of tensor calculus, gave a modern structure to the modeling of anisotropy (Voigt 1898, 1910). The following history is a recent one! For the mathematical treatment of anisotropic properties the treatise of Nye (1923-2019) is still fundamental (Nye 1985), while a 
concise history of the discovery of the physical properties of crystals was published by Wooster (1903-1984) (Wooster 1990). For an overview of the contributions of Crystallography to the development of the atomic theory of matter, I would like to point out my recently published article (Ferraris 2019).

\section{References}

Arago F (1811) Mémoire sur une modification remarquable qu'éprouvent les rayons lumineux dans leur passage à travers certains corps diaphanes et sur quelques autres nouveaux phénomènes d'optique. Mémoires de la classe des sciences mathématiques et physiques de l'Institut impérial de France 1811:93-134

Aquilanti V, Mottana A (2019) Topical collections on Lincei prizewinners. Rend Fis Acc Lincei 30(2):237-238

Bartholin E (1661) De figura nivis dissertatio. Matthiae Godicchii, Hafniae

Bartholin E (1669) Experimenta cristalli islandici disdiaclastici quibus mira and insolita refractio detegitur. Danielis Paulli, Copenhagen

Baur WH (2014) One hundred years of inorganic crystal chemistry-a personal view. Crystallogr Rev 20:64-116

Biot JB (1812) Mémoire sur un nouveau genre d'oscillation que les molécules de la lumière éprouvent en traversant certains cristaux. Mémoires de la Classe des sciences mathématiques et physiques de l'Institut impérial de France 1812:1-371

Biot JB (1817) Mémoire sur les rotations que certaines substances impriment aux axes de polarisation des rayons lumineux. Mémoires de l'Académie des sciences de l'Institut de France 2:41-136

Biot JB (1818) Mémoire sur les lois générales de la double réfraction et de la polarisation dans les corps régulièrement cristallisées. Mémoires de l'Académie Royale des sciences et de l'Institut de France 3:177-384

Biot JB (1839) Sur la cause physique qui produit le pourvoir rotatoire dans le quartz cristallisé. Comptes Rendus 8:683-691

Burke JG (1966) Origins of the science of crystals. University of California Press, Berkeley

Cauchy AL (1827) De la pression ou tension dans un corps solide. Exercices de Mathématiques 2:42-56
Ferraris G (2019) Early contributions of crystallography to the atomic theory of matter. Substantia 3(1):111-118

Fresnel A (1824) Considérations théoriques sur la polarisation de la lumière. Bulletin des Sciences par la Société Philomathique de Paris 1824:147-158

Fresnel AJ (1827) Mémoire sur la double réfraction. Mémoires de l'Académie Royale des sciences de 1'Institut de France 7:45-176

Haüy R (1784) Essai d'une théorie sur la structure des cristaux. Gogue $\&$ Nee de la Rochelle, Paris

Hooke R (1665) Micrographia or some physiological descriptions of minute bodies made by magnifying glasses with observations and inquiries thereupon. Jo. Martyn and Ja. Allestry, London

Huygens C (1690) Traité de la lumière. Pierre Vander Aa, Leiden

Kepler J (1611) Strena seu de nive sexangular. Godefredum Tampach, Frankfurt

Lima-de-Faria J (ed) (1990) Historical atlas of crystallography. Springer, Dordrecht

Malus ĖL (1809) Sur une propriété de la lumière réfléchie. Mémoires de Physique et de Chimie de la Société D’Arcueil 2:143-158

Mauskopf SH (1976) Crystals and compounds. Molecular structure and composition in nineteenth-century French science. Trans Am Philos Soc 66:1-82

Mitscherlich E (1824) Über das Verhältnis das Form des kristallisierten Körper zur Ausdehnung durch die Wärme. Poggendorff Annalen der Physik 1:125-127

Nye JF (1985) Physical properties of crystals: their representation by tensors and matrices. Clarendon Press, Oxford

Pasteur L (1848) Sur les relations qui peuvent exister entre la forme cristalline, la composition chimique et le sens de la polarisation rotatoire. Annales de Chimie et de Physique XXIV:442-459

Voigt W (1898) Die fundamentalen physikalischen Eigenschaften der Kristalle in elementarer Darstellung. Veit \& comp., Leipzig

Voigt W (1910) Lehrbuch der Kristallphysik. Druck und Verlag, Leipzig

Wooster WA (1990) A brief history of physical crystallography. In: Lima-de-Faria J (ed) Historical atlas of crystallography. Kluwer academic publishers, Dordrecht, pp 61-75

Publisher's Note Springer Nature remains neutral with regard to jurisdictional claims in published maps and institutional affiliations. 